\title{
Narratives of African-American Students: Bringing Diverse Voices into Classrooms
}

\author{
Dorota Celinska ${ }^{1, *}$ \\ ${ }^{1}$ Roosevelt University, Chicago, Illinois, USA \\ *Correspondence: College of Education, Roosevelt University, 18 S. Michigan Avenue, Chicago, IL 60603, USA. \\ E-mail: dcelinsk@roosevelt.edu
}

Received: June 15, 2015

Accepted: August 4, $2015 \quad$ Online Published: August 19, 2015

doi:10.5430/wjel.v5n3p1

URL: http://dx.doi.org/10.5430/wjel.v5n3p1

\begin{abstract}
Diverse learners may experience barriers to school success and/or be inappropriately placed in special education programs due to the traditional reliance on the deficit-based interpretation of their culture-based language use and discourse styles. This study focuses on early adolescents' narrative discourse, one of the critical linguistic factors linked to school success. Specifically, it compares personal and fictional narratives of African-American and Caucasian students from two narrative perspectives, one consistent with the prevalent classroom narrative expectations (Episodic Analysis) and the other congruent with culturally based narrative styles (High Point Analysis). By broadening the scope of narrative analysis beyond the conventional school-based approach, this study aims at providing a more culturally appropriate portrayal of narrative skills of African-American students and interpret it in congruence with culturally-based narrative styles. The participants were 82 students of varying levels of academic achievement and socio-economic backgrounds. Narrative performance is analyzed in terms of length, structural organization, and overall coherence, followed by examples of specific narrative patterns. The results indicate that when narratives are analyzed using High Point Analysis, African-American and Caucasian students demonstrate comparable performance in terms of the narrative length, structural organization and coherence. In contrast, the results of narrative analysis using Episodic Analysis that focuses on episodic organization promoted within the conventional school narrative expectations indicate several differences across the groups. The results may support educators in their attempts to encourage and facilitate diverse narrative voices in their classrooms, as well as maximize intellectual and socio-emotional benefits of narrative exchanges for African-American students.
\end{abstract}

Keywords: narrative discourse, narrative styles, adolescent narratives, diverse learners, African-American narrators

\section{Introduction}

\subsection{Introduce the Problem}

School success depends, among other factors, on student's involvement in classroom narrative discourse (Cazden, 1988; Gardner-Neblett, Pungello, \& Iruka, 2012; Gay, 2000; Lue, Green, \& Smalley, 2002; Wiley, 2005) and the congruence between home and school discourse forms (Champion, 2003; Snow, Burns, \& Griffin, 1998). According to Gee and Green (1998, pp.119-120), "discourse processes and practices shape what counts as knowing, doing, and being within and across events in classrooms." Competent narrators actively engage in classroom verbal exchanges and school tasks (Cazden, 1999; Hicks, 1996), becoming a part of "dynamic social process for accomplishing complex conceptual and communication goals" that enhances their academic learning and critical thinking skills (Cazden, 1999, p. 31). Since narrative style is significantly impacted by cultural factors (Gay, 2000), culturally and linguistically diverse students who use discursive styles incongruent with school expectations may encounter obstacles to school success (Gee \& Green, 1998; Gay, 2000).

\subsection{Explore Importance of the Problem}

Historically, research has shown that African American students whose narrative performance mismatch school narrative expectations often struggle with academic achievement and engagement (Bloome, Katz, \& Champion, 
2003; Champion, 2003; Hester, 1996; Michaels, 1991; Silliman, Wilkinson, \& Turner, 2002). Furthermore, African American students have been overrepresented in special education programs (Klingner at al., 2005; Donovan \& Cross, 2002; Skiba, Poloni-Staudinger, Gallini, Simmons, \& Feggins-Azziz, 2006), perhaps due to interpreting culture-based language use as a barrier to school success (Artiles, 2002; Gutierrez \& Rogoff, 2003). Specifically, predominantly mainstream educators typically evaluate performance of culturally diverse students against White middle-class standards and fail to discriminate between potential intrinsic deficits and cultural-linguistic characteristics. Consequently, many teachers interpret diverse students' performance as deficient (Gay, 2000; Klingner et al., 2005), perceive them as less capable of learning, and/or lower expectations for achievement (Gardner-Neblett et al., 2012; Kea \& Utley, 1998).

\subsection{Describe Relevant Scholarship}

The importance of narrative discourse for school engagement and achievement stems from its role in children's conceptual, social and academic development. Used of in a variety of instructional activities, readings/materials, and assessments (e.g., Gay, 2000; Hicks, 1993; Petersen \& Spencer, 2013), narrative discourse provides a distinct framework to represent knowledge of human action and social interaction (Bruner, 1991). In classrooms, narrative-based instruction mediates and expands children's conceptual understandings and problem-solving abilities through applications of abstract concepts to personal experiences (Bruner, 1991). For example, diverse adolescents' figurative language development has been successfully facilitated as a result of using a narrative format of content presentation (Quall, O’Brien, Blood, \& Hammer, 2003). Furthermore, classroom narrative-based activities allow students to engage in specific identities, attitudes, and social interactions (Gee \& Green, 1998; Moore, 2004). As contextualized generalizations about beliefs and values, narratives facilitate children's socialization into, and understanding of, social behavioral expectations (Stein, 1988). Importantly, children's socially-based narrative themes constitute an important mechanism for communicating their social and cultural identities. During classroom narrative exchanges students negotiate common cultural meanings, establish new social relationships (Hicks, 1993) and contribute to classroom communities (Dyson, 1994). As a result, classroom narratives allow children to "play with social and cultural lines influenced by age, sex, class, race, ethnicity" and become "vehicles for bringing diverse voices into the classroom itself" (Dyson, 1994, p. 168).

Given the cognitive and social narrative benefits, it is not surprising that narrative competence has been linked to academic success (Gardner-Neblett et al., 2012; McCabe, 1997; Roth, Speece, Cooper, \& De La Paz, 1996) and engagement in classroom tasks (Hicks, 1996). Through narrative exchanges with teachers, students explore meanings in curricular texts that lead to attainment of deep understandings of textual verbal concepts and implicit meanings (Blank, 2002). Correlational studies have linked children's narrative skills to concurrent and future reading achievement (Hester, 2010; Reese, Suggate, Long, \& Schaughency, 2010b). In general, young children's acquisition of specific oral narrative forms has been associated with their later successful transition to emergent reading (Curenton, 2011; Dickinson, Golinkoff, \& Hirsh-Pasek, 2010). Similarly, narrative production skills of kindergarteners who were enrolled in Head Start starting at 3 years of age were one of the four measures that correlated significantly with their subsequent fourth- and seventh-grade levels of reading comprehension and receptive vocabulary (Tabors, Snow \& Dickinson, 2001). A relationship between narrative performance and reading achievement has also been established for older struggling readers who have made a successfully transition to fluent reading (Roth et al., 1996). Further evidence of the critical role of narrative skills in literacy achievement of students from diverse backgrounds and varying levels of literacy attainment is provided by the results of the studies on the effectiveness of narrative-based literacy interventions. When literacy instruction to urban low income preadolescent and adolescent struggling readers and writers was enhanced by incorporating the narrative mode of thinking and their preferred narrative styles, these students demonstrated improved reading and vocabulary comprehension along with increased reading task engagement (Gay, 2000; Zigo, 2001). For instance, they developed new textual interpretations and critical evaluations that lead to deeper, integrated knowledge of text and more complex literary responses as a result of opportunities to relate textual content to personal narratives.

Paradoxically, in the context of the effectiveness and wide-spread use of narrative-based instruction, most teachers in urban public schools almost exclusively promote one specific narrative style, namely essayist or topic-centered narrative. Since topic-centered narratives aim at conveying information in the form of chronology of events, teachers typically encourage narratives that report events about a single time and place, relate parts to each other and to a cumulative component, and lead to a distinctive closure (Michaels, 1991). Consequently, teachers value, model and reinforce the clarity of descriptive detail, distinctive focus on the essential features, and concise organization while they discourage personal or cultural interpretation of the reported narrative events (Michaels, 1991). Importantly, topic-centered narrative closely approximates the descriptive expository written expression format (Gay, 2000; Hicks, 
1993; Michaels, 1991) and is consistent with narrative forms valued and practiced in White middle-class communities (Hicks, 1993).

Under such circumstances some culturally/linguistically diverse students may have limited access to the benefits of classroom narrative-based learning activities. In particular, African American children of varying socioeconomic backgrounds display a wide array of narrative structures and often outperform their Caucasian peers on in terms of the complexity of narrative organization of their oral narratives (Currenton, 2011; Price, Roberts, \& Jackson, 2010; Leyva, Sparks, \& Grolnick, 2010a) as well as written narratives (Nelson \& VanMeter, 2007). For example, Schachter and Craig (2013) indicated that the use of African American English (AAE) contributed to the complexity of narrative structures produced by low- and mid-socioeconomic status kindergarten and first grade students. However, equipped with flexibility in narrative style, African American students may prefer narrative styles incongruent with the expected topic-centered narrative performance (Mainess, Champion, \& McCabe, 2002; Schick \& Melzi, 2010). For example, African American first-graders who showed comparable to their White peers' ability to adjust narrative styles differed as to how they interpreted narrative tasks based on their prior narrating experiences with their communities (Hicks, 1993). Low-income African American children, have been shown to prefer to use episodic or topic-associating narrative forms in which a variety of lexical and intonation strategies are used to present narrative events through a sequence of frequent shifts in time, place, and characters (Champion, 2003; Hicks, 1993; Michaels, 1991). The narrator juxtaposes a series of thematically related episodes/anecdotes so that the relationships among narrative components remain implicit. As the structure of a narrative unfolds in a circular manner through overlapping and intersecting thoughts, the listener is expected to infer them on his/her own (Bidell, Hubbard, \& Weaver, 1997; Gay, 2000). In this fashion, topic-associating narratives simultaneously accomplish multiple purposes including relating information, persuading a point of view, social networking, and self-expression. In sharp contrast to topic-centered narratives, this style utilizes narrative structure that "introduces a theme with a strong emotional content (...), expands on this same theme, and then closes with a final repetition of the theme” (Bidell, et. al., 1997; p. 5). Furthermore, African American students may prefer to narrate in a manner consistent with participatory-interactive communication style in which speakers and listeners engage each other in an expressive and overlapping manner (Gay, 2000; Labov, 1972; Wiley, 2005). For example, during call-response, the listeners are expected to verbally and nonverbally respond to the speaker's statements (i.e., calls) in order to signal an accomplishment of his/her discursive purposes (Champion, 2003; Gay, 2000). In this format, performative narratives are co-constructed through speaker-audience interactions (Gay, 2000), with the purpose of expressing the narrator's social identity and building the relationship between the narrator and audience (Bloome, et. al, 2003; Champion, 2003). In this vein, performative narrative style is contrary to the conventional passive-receptive classroom discourse in which teachers dominate classroom talk, grant students permission to talk one at a time, and encourage brief and explicit narrations that refrain from emotional and personal expressions (Cazden, 1988, 1999; Gay, 2000).

Children who produce literate-like, topic-centered narratives conforming to the forms expected at school tend to receive teacher appreciation and are afforded extended practice in oral discourse and literacy through teacher-guided dialogic exchanges (Gay, 2000; Michaels, 1991), along with becoming more engaged classroom community members (Cazden, 1999; Michaels, 1991). Furthermore, they participate in classroom discourse and dialogue with teachers more effectively and become more competent writers (Michaels, 1991). On the contrary, teachers who are unfamiliar with the narrative styles of diverse students may perceive their narratives as disorganized, deficient, and not conducive to intellectual learning, and, therefore refrain from dialogs to elaborate on these narratives and/or appreciation of the child's narrative expressions (Gay, 2000; Labov, 1972; Michaels, 1991; Wiley, 2005). In addition, a mismatch between the child's narrative style and teacher narrative expectations may results in an inappropriate appraisal of the child's competencies, lowering academic expectations, changing attitudes toward the child as a learner, and/or regarding a student as having a learning disability or language delay (Champion, 2003; Currenton, 2006; Gay, 2000; Michaels, 1991).

\subsection{State Hypotheses and Their Correspondence to Research Design}

This study compares personal and fictional narratives of African-American and Caucasian students from two narrative perspectives, one consistent with the prevalent classroom narrative expectations and the other congruent with culturally based narrative styles. By broadening the scope of narrative analysis beyond the conventional school-based approach, this study aims at providing a more culturally sensitive representation of narrative abilities of African-American students. Equipped with a more culturally appropriate portrayal of narrative skills of these students, educators may develop new insights into their narrative competencies and preferences. Most importantly, educators may, as a result of this new knowledge, become more appreciative of narrative exchanges African-American students offer and foster diverse narrative voices in their classrooms. 


\section{Method}

\subsection{Study Conceptual Framework}

This study uses two complimentary narrative approaches, Episodic Analysis (EA) and High Point Analysis (HPA) to compare the length, structural organization, and coherence of the participants' personal and fictional narratives. As one of the story grammar approaches, EA analyzes narratives through the lenses of the relationships within problem-solving behavior sequences (i.e., goal-attempt-outcome) (Stein, 1988; Stein \& Albro, 1997). Its prototypic narrative, story, closely resembles the common school-based expectations for children's narrative performance, that is topic-centered narrative style (see discussion above). In contrast, HPA dismisses the view of narrative as a "window" to knowledge of human behavior, and instead postulates that narratives are linguistic representations of experience formulated for communicative purposes. Consequently, it assumes that narrative coherence emerges from the narrator's expressions of personal significance of the recounted events. Expanding on its roots in sociolinguistic analysis of performance of African American narrators, HPA has been utilized to explore narratives of African American children in order to address their unique communicative needs through culturally relevant pedagogy (Champion, 2003; Labov, 1972) and to expand deficit-based interpretations of their narrative performance (Celinska, 2009).

\subsubsection{Episodic Analysis: Assumptions and Prototypic Narrative}

Developed within the theoretical tradition of cognitive psychology, Episodic Analysis (EA) views narrative structures as representations of the narrator's schematic knowledge of events, called "story schemas" or "story grammars" (Stein, 1988). Assuming that stories "are reflections of the social values, beliefs, and goals that underline and motivate human interaction” (Stein, 1988, p. 282), EA recognizes traditional folk tales as the prototypic narrative form that best reflects the knowledge of human intentionality and goal-directed behavior. Inspired by the literary studies of folktales, EA explores children's mastery of the basic unit of story organization, episode, that comprises a sequence of goal-directed actions in which the character's thoughts and feelings are causally related to his/her behavior (i.e., the goal-attempt-outcome sequences).

EA assumes that stories are composed of two discrete structural components: setting and episode(s). Setting introduces the characters and describes the spatial and temporal context of a story. Episode is composed of the following discrete categories: (1) Initiating Event that presents a change in the environment that leads to the protagonist's responses, (2) Internal Responses that are goals, thoughts, and feelings of the protagonist that result in setting a goal and a plan, (3) Attempts that reflect the protagonist's goal-oriented actions, (4) Direct Consequences that refer to the attainment of goal(s) and the changes that resulted from the attempt(s), and (5) Reactions that include the protagonist's thoughts and feelings related to the outcomes of his/her actions. Developmental research (Stein, 1988; Stein \& Albro, 1997) revealed the sequence in children's mastery of episodic organization based on the growing complexity of goal-directed action sequences (Stein, 1988; Stein \& Albro, 1997). The least advanced story structure, a Descriptive Sequence, consists of descriptions of characters, actions, and settings that are temporally or causally unrelated. When children begin to connect story events, two possible story structures appear: an Action Sequence in which actions are temporally related or a Reactive Sequence in which actions are linked both temporally and causally but are not goal-directed. In contrast, an Abbreviated Episode includes events that are causally structured into episodes and a goal of the protagonist is present. Although this pattern contains an intact episode with a goal, attempt, and outcome, two components of a Complete Episode are missing: an obstacle to goal attainment and an ending.

\subsubsection{High Point Analysis: Assumptions and Prototypic Narrative}

In contrast to EA's focus on stories, High Point Analysis (HPA) analyzes personal narratives because this genre best captures the dual function of narrative, namely recounting past events (the referential function) and expressing the subjective meaning of these events (the evaluative function) (Labov, 1972). By analyzing both the narrative events and their personal significance, HPA is uniquely suited to reveal personal meaning that narrators impose on the recounted events with the intent to express their individual and cultural identities. The overall narrative coherence emerges from organizing narrative events around a single event of particular significance to the narrator. As a sociolinguistic approach, HPA utilizes narrative functional communicative analysis originally derived from a study of personal narratives told in natural social situations and naturalistic interviews by 10 to 72 year old African-American and Caucasian narrators from rural and urban settings (Labov, 1972). Further refinement of this approach resulted from an analysis of personal narratives of south-central Harlem preadolescents and adolescents from "the black English vernacular culture” (Labov, 1972, p. 355). 
The referential narrative function provides information on the temporal and spatial circumstances of the reported events, introduces the characters, and recounts the sequence of the events. The evaluative function expresses the narrator's attitude toward the reported events, reveals the meaning of the events to the narrator, and describes the narrator himself. The evaluative function may permeate the entire narrative; however it is particularly concentrated at a high point, or climactic moment of the account, immediately preceding the resolution of the conflict. To identify the evaluation of the narrative it is necessary to establish "why the events of the narrative are reportable" (Labov, 1972, p. 370). Most commonly, the evaluation portion of the narrative signals that something "was strange, uncommon, or unusual - that is, worth reporting" (Labov, 1972, p. 371). A prototypical personal narrative, called Classic narrative, is composed of the following (Labov, 1972): (1) Abstracts and Introducers that are introductory statements that encapsulate the whole narrative, (2) Orientations that describe the temporal, spatial, and situational context of the events, (3) Complicating actions that contain a sequence of chronologically-ordered events leading up to and including the high point, (4) Evaluations that reveal the narrator's personal meaning of the events, (5) Resolution that follows the high point to resolve any complication included in the narrative, and (6) Coda, final statements that close the narrative and/or relate it to the present communicative context.

Research (Peterson \&McCabe, 1983) revealed five developmental patterns of narrative coherence in addition to Classic narrative pattern. The least developed narrative structure, Leap-frog narrative, is composed of incomplete and/or disorganized events that fail to represent the original events. Impoverished narrative includes insufficient number of events and usually is restricted to orientation, evaluation, and repetition of narrative components. Disoriented narrative is usually contradictory, and seems to reflect the child's confusion about the narrated events or the child's difficulty with language. Chronological narrative consists of a temporally organized sequence of discrete, independent events that occur within a specific time period, or a list of events without recognizing any particular one as a high point. In contrast, Ending-at-the-High-Point narratives provide successive complicating actions until the high point is reached without resolving the central conflict of a narrative.

\subsection{Participant Characteristics}

The participants were 34 African American (AA group) and 48 Caucasian (C group) students from eleven suburban and four urban schools (54 and 28 students, respectively) located in a Midwest metropolitan area. African-American participants attended urban and suburban schools (28 and 6, respectively) while all Caucasian participants were enrolled in suburban schools. The participants were enrolled in four grade levels, as follows: $4(\mathrm{~N}=17), 5(\mathrm{~N}=46), 6$ $(\mathrm{N}=17)$, and $7(\mathrm{~N}=2)$. Forty one boys and 41 girls participated, and were equally distributed at each grade level. Thirty five percent of the participants were eligible for free or reduced lunch (26 African-American from urban schools and 3 Caucasian). All participants were native English language speakers.

\subsection{Sampling Procedures}

Half of the participants in each group were identified as having a learning disability by their schools and were matched individually with the typically achieving peers within the group for chronological age, grade, and gender. Author's review of these students' most recent case study evaluations and/or IEPs revealed that a higher proportion of African-American than Caucasian participants had identified difficulties in reading, writing and math. Further, African American participants received instruction in more restrictive environments, as evidenced by the fact that 24 Caucasian and 8 African-American students received more than $50 \%$ of instruction in general education settings, whereas 9 African-American received less than $50 \%$ of instruction in this setting.

\subsection{Narrative Collection and Coding}

Narratives were collected by adapting the conversational map, a protocol for naturalistic narrative elicitation during conversation (Peterson \& McCabe, 1983). The interviewer, a Caucasian female graduate student, initiated a casual conversation and prompted narrating on topics of interest to the student using open-ended questions. Subsequently, the interviewer told short narratives about common experiences of potential interest to the participants (e.g., trip adventures) to further engage the interviewees in narrating. Throughout the 20- to 30- minute interview, the interviewer encouraged (without leading) the participants to narrate about events of personal significance and showed interest in all narratives regardless of their thematic and structural features. At the conclusion of the interview, the interviewer explicitly prompted the student to tell a fictional (make-believe) story of his/her choice. All interviews were audiotaped and transcribed verbatim. Masked transcripts (based on audiotapes) were coded to mark the following five types of the HPA Evaluations: Onomatopoeia (an imitation of an environmental sound or object), Stress (a marked emphasis in voice), Elongating (marked drawing out of words/sounds), Exclamation (increased voice volume), and Imitation of human voice (a change in the narrator's speech to mark the qualities of characters' speech) (Peterson \& McCabe, 1983). Inter-rater agreement for 20\% of randomly selected transcripts yielded a $91 \%$ 
agreement for number of components and a 98\% agreement for type of component. Subsequently, personal narratives were identified in the transcripts using Labov's definition of a minimal narrative as "a sequence of two clauses which are temporally ordered" (Labov, 1972, p. 360). The three longest of each participant's personal narratives (in clauses) were selected (with the exception of 6 African-American participants who produced only two narratives), resulting in 144 narratives from Caucasian and 96 narratives from African-American participants. The total of 82 fictional narratives was analyzed, one from each participant.

Narratives were broken into syntactic clauses defined as "logical sequences of words containing a subject and a verb" (Friend, 1976, p. 31). Each clause was classified as either independent clause (i.e., a clause that represents a complete thought) or a dependent clause (i.e., a clause that has an incomplete meaning) (Friend, 1976). The inter-rater agreement for $18 \%$ of randomly selected transcripts yielded a $95 \%$ agreement for number of clauses and a $97 \%$ agreement for type of clause. Independent clauses were further coded as an Orientation, Evaluation, Complicating action, Resolution, or Appendage (inclusive of Abstracts, Introducers, and Codas), and additionally as Evaluation, if appropriate. Dependent clauses were coded as either Orientation or Evaluation. The inter-rater agreement for $18 \%$ of randomly selected transcripts yielded an $87 \%$ agreement for the type of component. Further, each personal and fictional narrative was categorized into one of the six coherence patterns: Leap-frogging, Impoverished, Disoriented, Chronological, Ending-at-the-high-point, and Classic. The inter-rater agreement for $18 \%$ of randomly selected transcripts yielded an $86 \%$ agreement for the type of pattern.

Following the above HPA coding, narratives were divided into propositions that consist of a predicator or relational word (usually the verb) and one or more arguments which stand in some specific relation to the predicator (Fillmore, 1968). The inter-rater agreement for $15 \%$ of randomly selected transcripts yielded a $96 \%$ agreement for number of propositions. Each proposition was then classified as Setting, Initiating Event, Internal Response, Attempt, Direct Consequence, or Reaction. The inter-rater agreement for 15\% of randomly selected transcripts yielded an $85 \%$ agreement for the type of component. Next, narratives were categorized into one of the five coherence patterns: Descriptive Sequence, Action Sequence, Reactive Sequence, Abbreviated Episode, or Complete Episode. The inter-rater agreement for $15 \%$ of randomly selected transcripts yielded an $88 \%$ agreement for type of pattern.

\subsection{Research Design}

African-American (AA group) and Caucasian (C group) participants were compared on the following three dependent measures:

1. Length in terms of the mean number of: (a) clauses per narrative, (b) propositions per narrative, (c) propositions per episode, and (d) episodes per narrative.

2. Structural organization in terms of the mean proportion of: (a) clauses per narrative classified into each of the HPA five structural components and (b) propositions per narrative classified into each of the EA six structural components.

3. Coherence in terms of the mean proportion of narratives classified into: (a) each of the six HPA patterns and (b) each of the five EA patterns.

\section{Results}

\subsection{Recruitment}

All participants recuited participated in the study and completed all measures as described above.

\subsection{Statistics and Data Analysis}

A series of one-way ANOVAs were conducted to detect group differences, with the level of significance for all analysis adjusted to control for Type I error by dividing .05 by the number of $F$ tests (separately for personal and fictional narratives). The results indicate that, compared to their Caucasian peers, African-American students produced personal (but not fictional) narratives that were significantly shorter in terms of the number of propositions per narrative ( $\mathrm{AA}=15.1$ and $\mathrm{C}=16.3, F(1,78)=8.08, p=.006$ ) (see Table 1 ). Narratives 1 and 2 exemplify the difference in the overall narrative length measured by the number of propositions. 
Table 1. Comparison of AA and C groups on Narrative Length in Personal and Fictional Narratives

\begin{tabular}{|c|c|c|c|c|c|c|}
\hline \multirow[b]{2}{*}{ Length measure/Genre } & \multicolumn{2}{|c|}{ AA } & \multicolumn{2}{|c|}{$\mathrm{C}$} & \multirow[b]{2}{*}{$F(1,78)$} & \multirow[b]{2}{*}{$p$} \\
\hline & $\mathrm{M}$ & SD & $\mathrm{M}$ & SD & & \\
\hline \multicolumn{7}{|l|}{ Clauses per narrative } \\
\hline Personal & 14.5 & 10.5 & 15.6 & 10.3 & .20 & .657 \\
\hline Fictional & 37.6 & 35.5 & 25.7 & 19.9 & 3.65 & .060 \\
\hline \multicolumn{7}{|l|}{ Propositions per narrative } \\
\hline Personal & 15.1 & 11.3 & 16.3 & 11.4 & 8.08 & $.006 *$ \\
\hline Fictional & 39.7 & 37.3 & 25.7 & 21.5 & 4.48 & .037 \\
\hline \multicolumn{7}{|l|}{ Propositions per episode } \\
\hline Personal & 8.6 & 2.7 & 11.1 & 5.2 & 6.99 & $.010 *$ \\
\hline Fictional & 7.1 & 2.5 & 10.0 & 2.3 & .28 & .600 \\
\hline \multicolumn{7}{|l|}{ Episodes per narrative } \\
\hline Personal & 2.1 & 2.5 & 1.9 & 1.3 & 36.44 & $.000 *$ \\
\hline Fictional & 3.5 & 2.7 & 2.3 & 1.6 & 6.87 & $.011 *$ \\
\hline
\end{tabular}

* Significant differences. The level of significance adjusted to .0126 .

Narrative 1:

It was third grade. And he had failed two times. He was supposed to be in the fifth and he was much bigger than I was. So I didn't even know what to do. He wanted to fight one day. And I did. I won. And he left me alone.

Narrative 2:

You know what happened? I was in an All Star game for baseball. And I was up against one of the fastest pitchers. And I was a little nervous and everything. And then (I I didn't think) you know I was thinking "Oh, I'm never gonna hit a ball against him." And then I hit it. And it went oooou. And then I heard "Dooong." I hit a car. But you know what? You know what it turned out to be? It turned out to be my mom's car. I hit my own mom's car. And then a few innings later someone else hit it. Luckily (we we) it was like an old van and (she just) she bought a new one so. It was like "Dong" right here. And on the other side "Dong" right there. Mine was the biggest. It's not as bad as across the street where they put too many bikes on a bike rack. And it went like "tchoo" and there is like three exact dents on the back of their trunk. It's funny.

Similarly, African-American students' personal (but not fictional) narratives were significantly shorter in terms of the number of propositions per episode (AA=8.6 and $\mathrm{C}=11.1, F(1,78)=6.99, p=.010)$. In both personal (AA=2.1 and $\mathrm{C}=1.9, \quad F(1,78)=36.44, p=.000)$ and fictional $(\mathrm{AA}=3.5$ and $\mathrm{C}=2.3, F(1,78)=6.87, p=.011)$ narratives, African-American participants produced significantly more episodes per narrative (see Table 1). Narrative 3 consists of multiple short episodes while Narrative 4 is build of a single longer episode.

Narrative 3:

Two weeks later I went to her, asked "Gloria and Jessica there?" Her auntie said "No!" Then so I start crying because it was my best friend. And I just kept going over there and over there asking her do she know where she live. "Do you know the school she go to? They told me but I forgot. So I went home thinking about it, praying about it. If you can let me see her face. It was this one time. I was walking down their block and there was some kids on the porch. And I called Jessica name but she looked back and I turned my head. So came back to school. I told my other best friend about it.

Narrative 4:

So I was at the church with my dad 'cause it was like Saturday. And I was climbing a tree. And then I didn't know it was a hornet's nest at the time. So there was like a huge bee nest. It was probably like the back of this chair, that big. And so I thought it was a big pear 'cause it was on a pear tree. So I was like oh if I can get this for my mom, she's gonna be very happy with it. So but like I was maybe two feet away from it and I couldn't get any branches so I just hacked the pear. And it fell to the ground. And I jumped down and I got it. And a bee was in it which I didn't see. And then I told my mom what I saw. And she's like “Good thing you didn't get it."

Further, African-American participants included a significantly higher proportion of Internal Responses in personal (but not fictional) narratives (AA=.10 and $\mathrm{C}=.05, F(1,78)=8.40, p=.005$ ) (see Table 2). Narrative 5 and 6 illuminate the difference regarding the inclusion of Internal Responses, with the former including more prepositions in this category. 
Table 2. Comparison of AA and C Groups on Narrative Structural Organization of Episodic Analysis in Personal and Fictional Narratives

\begin{tabular}{lllllll}
\hline & \multicolumn{9}{c}{ AA } & \multicolumn{1}{c}{ C } & \\
\cline { 2 - 7 } Component/Genre & $\mathrm{M}$ & $\mathrm{SD}$ & $\mathrm{M}$ & $\mathrm{SD}$ & $F(1,78)$ & $p$ \\
\hline Setting & & & & & & \\
$\quad$ Personal & .29 & .13 & .34 & .10 & 4.40 & .039 \\
$\quad$ Fictional & .33 & .14 & .30 & .15 & .72 & .398 \\
Initiating Event & & & & & & \\
$\quad$ Personal & .22 & .10 & .19 & .08 & 1.95 & .166 \\
$\quad$ Fictional & .15 & .08 & .21 & .16 & 4.19 & .044 \\
Internal Response & & & & & & \\
$\quad$ Personal & .10 & .09 & .05 & .06 & 8.40 & $.005^{*}$ \\
$\quad$ Fictional & .08 & .08 & .09 & .11 & .70 & .404 \\
Attempt & & & & & & \\
$\quad$ Personal & .10 & .10 & .08 & .08 & 1.37 & .245 \\
$\quad$ Fictional & .14 & .14 & .14 & .15 & .01 & .935 \\
Direct Consequence & & & & & & \\
$\quad$ Personal & .23 & .11 & .25 & .09 & .87 & .355 \\
$\quad$ Fictional & .25 & .13 & .18 & .12 & 4.82 & .031 \\
Reaction & & & & & & \\
$\quad$ Personal & .04 & .07 & .07 & .07 & 2.67 & .106 \\
$\quad$ Fictional & .05 & .07 & .05 & .07 & .04 & .836 \\
\hline
\end{tabular}

* Significant differences. The level of significance adjusted to .008 .

Narrative 5:

And plus I've been in there when a tree branch fell on me and my head cracked open. I had to get stitches. (Uhm) my friend had a tire swing in her back yard. And it was on a branch. And the branch they found out later must've been dead. And we were swinging. And all of a sudden I hear this big like ear splitting crack. And it almost sounds like water being poured over like a balcony or something. It was kinda of a weird sound. And then like I see these like leaves falling in front of me. And my friend jumps out of the way and she tries to grab me. But then all of a sudden I like see leaves coming down. And all of a sudden I feel this big thud in my head. It's like cracked open and my shirt is all bloody. And people are running across the fence. And then I'm on that deck on like a stretcher. And then I remember going to the hospital in my neighbor's car. And then I remember getting stitches. I actually don't remember too much about the actual thing that happened, the actual accident. But I do remember on the way there and on the way back. And it happened in the summer so that kinda ruined my summer vacation. But I was better maybe about in a week or so. So now I don't go on the tire swings that are attached to branches any more. I'm sorry. I'm just not going. I'll go on one that are attached to like poles but not on trees. I'm sorry. This is not going to happen again.

Narrative 6:

And one time I had a sliver, a big sliver in my foot because we have like a big deck. I went out there one day without no shoes and I slipped because there was water there. And this big sliver right went into my foot. And I still have this. It's in five pieces. And I had to get stitches. They had to give me a shot first. And then I didn't feel a thing because they were cutting my foot open.

African-American participants' fictional (but not personal) narratives were significantly less often in the form of Complete Episode (AA=.05 and $C=.08, F(1,78)=7.26, p=.009$ ) (see Table 3). Narrative 7 exemplifies a Complete Episode and is in contrast to both Narrative 8, an example of Action Sequence and Narrative 9, an example of Abbreviated Episode. 
Table 3. Comparison of AA and C Groups on Narrative Coherence Patterns of Episodic Analysis in Personal and Fictional Narratives

\begin{tabular}{lllllll}
\hline \multirow{2}{*}{ Pattern/Genre } & \multicolumn{7}{c}{ AA } & \multicolumn{1}{c}{ C } & \\
\cline { 2 - 7 } Descriptive Sequence & M & SD & M & SD & $F(1,78)$ & $p$ \\
$\quad$ Personal & .08 & .12 & .06 & .12 & .79 & .377 \\
$\quad$ Fictional & .03 & .09 & .07 & .19 & 1.12 & .294 \\
Action Sequence & & & & & & \\
$\quad$ Personal & .12 & .23 & .16 & .22 & .54 & .466 \\
$\quad$ Fictional & .18 & .25 & .07 & .20 & 5.52 & .021 \\
Reactive Sequence & & & & & & \\
$\quad$ Personal & .65 & .24 & .68 & .28 & .17 & .679 \\
$\quad$ Fictional & .49 & .36 & .48 & .40 & .01 & .910 \\
Abbreviated Episode & & & & & & .946 \\
$\quad$ Personal & .06 & .13 & .06 & .13 & .01 & .069 \\
$\quad$ Fictional & .19 & .31 & .09 & .21 & 3.40 & \\
Complete Episode & & & & & & .372 \\
$\quad$ Personal & .05 & .11 & .08 & .19 & .81 & $.009 *$ \\
$\quad$ Fictional & .10 & .23 & .30 & .42 & 7.26 & \\
\hline
\end{tabular}

*Significant differences. The level of significance adjusted to .010.

Narrative 7:

Once upon a time there was a boy and a grandfather. The boy's name was David and the grandfather's name was Tinchy. And they lived in a small house. And one day a man from far away came and took David's grandfather. So David gathered up his things and went to find him. So he traveled to an island where he thought his grandfather had been taken. And he found a castle. And he thought his way in and found that his grandfather was in a cell in a dungeon room. So he thought the guard that had the keys and opened it. And then since there were too many guards around them they had to fight them off. And they took one of the castle's boats and sailed back home. And they lived happily ever after.

Narrative 8:

Once there was a dog who was running in the street. And he got hit by a car. Then he had to go to the vet and he was there for a week. And he went home. And then he was chasing a cat. And then the cat got scared and ran into a fence. And then the dog grabbed him by the tail. And the squirrel saw the dog. And then the dog ran after the squirrel. And then the squirrel fell of the fence. And this person saw the squirrel and got it and bring it to his house. And then he had a dog. And the dog was like trying to get it. And then the dog got hurt.

Narrative 9:

Once was a cat. And the cat wanted to talk to people. So it, the cat was trying to learn how to talk and bumped into this one magical person. And the person put magic on the cat so the cat could talk to people. And the cat kept talking to people. And whenever someone was hurt the cat would go and talk. And it made people feel better.

There were no significant group differences on the HPA measures of length (see Table 1 above), structural organization (see Table 4), or coherence (see Table 5) for either personal or fictional narratives. 
Table 4. Comparison of AA and C groups on Narrative Structural Organization of High Point Analysis in Personal and Fictional Narratives

\begin{tabular}{|c|c|c|c|c|c|c|}
\hline \multirow[b]{2}{*}{ Component/Genre } & \multicolumn{3}{|c|}{ AA } & \multicolumn{3}{|l|}{$\mathrm{C}$} \\
\hline & $\mathrm{M}$ & SD & $\mathrm{M}$ & SD & $F(1,78)$ & $p$ \\
\hline \multicolumn{7}{|l|}{ Complicating Action } \\
\hline Personal & .40 & .14 & .38 & .11 & .23 & .634 \\
\hline Fictional & .41 & .16 & .39 & .17 & .57 & .451 \\
\hline \multicolumn{7}{|l|}{ Resolution } \\
\hline Personal & .03 & .04 & .04 & .07 & .66 & .420 \\
\hline Fictional & .03 & .04 & .04 & .07 & 1.43 & .236 \\
\hline \multicolumn{7}{|l|}{ Appendages } \\
\hline Personal & .05 & .06 & .04 & .04 & .18 & .673 \\
\hline Fictional & .02 & .03 & .01 & .03 & .64 & .425 \\
\hline \multicolumn{7}{|l|}{ Orientation } \\
\hline Personal & .32 & .12 & .34 & .13 & .53 & .469 \\
\hline Fictional & .34 & .18 & .39 & .15 & 1.47 & .230 \\
\hline \multicolumn{7}{|l|}{ Evaluation } \\
\hline Personal & .34 & .14 & .40 & .15 & 3.29 & .074 \\
\hline Fictional & .30 & .20 & .32 & .17 & .21 & .651 \\
\hline
\end{tabular}

* Significant differences. The level of significance adjusted to .010.

Table 5. Comparison of AA and C Groups on Narrative Coherence Patterns of High Point Analysis in Personal and Fictional Narratives

\begin{tabular}{|c|c|c|c|c|c|c|}
\hline \multirow[b]{2}{*}{ Pattern/Genre } & \multicolumn{2}{|r|}{$\mathrm{AA}$} & \multicolumn{2}{|c|}{$\mathrm{C}$} & \multirow[b]{2}{*}{$F(1,78)$} & \multirow[b]{2}{*}{$p$} \\
\hline & M & SD & $\mathrm{M}$ & SD & & \\
\hline \multicolumn{7}{|l|}{ Classic } \\
\hline Personal & .36 & .32 & .34 & .32 & .06 & .805 \\
\hline Fictional & .47 & .51 & .56 & .50 & .66 & .418 \\
\hline \multicolumn{7}{|c|}{ Ending-at-the-high-point } \\
\hline Personal & .11 & .19 & .16 & .22 & 1.06 & .306 \\
\hline Fictional & .00 & .00 & .04 & .20 & 1.47 & .229 \\
\hline \multicolumn{7}{|l|}{ Chronological } \\
\hline Personal & .35 & .32 & .27 & .30 & 1.38 & .244 \\
\hline Fictional & .35 & .49 & .27 & .44 & .63 & .432 \\
\hline \multicolumn{7}{|l|}{ Leap-frogging } \\
\hline Personal & .05 & .14 & .03 & .12 & .23 & .634 \\
\hline Fictional & .12 & .33 & .02 & .14 & 3.33 & .072 \\
\hline \multicolumn{7}{|l|}{ Impoverished } \\
\hline Personal & .13 & .26 & .15 & .25 & .18 & .673 \\
\hline Fictional & .03 & .17 & .08 & .28 & .99 & .321 \\
\hline
\end{tabular}

* Significant differences. The level of significance adjusted to .010 .

\section{Discussion and Conclusions}

In the milieu of African-American students' historical achievement gap and overrepresentation in special education, creating opportunities for increasing academic attainment and school engagement remains an unfulfilled educational mandate. One such opportunity lies in the domain of student meaningful participation in classroom narrative discourse and narrative-based instruction. In order to assure that African-American students have full access to the 
intellectual and socio-emotional benefits of narrative-based learning, educators must become fully aware and appreciative of the wide array of their culturally-based narrative styles (Dickinson et al., 2010; Gardner-Neblett et al., 2012; Godley, Sweetland, Wheeler, Minnici, \& Carpenter, 2006). Consequently, educators may favorably appraise such narrative repertoire and engage in student-teacher dialogs to build bridges between student experiences represented in their narratives and curricula concepts and school competencies. Simultaneously, educators create classroom communities of engaged learners whose expressions of individual and cultural identities are invited and rewarded.

The current results offer several insights that may assist educators in creating classrooms inclusive of diverse narrative voices. Importantly, when narratives (personal and fictional) are analyzed using High Point Analysis, African-American and Caucasian students demonstrate comparable performance in terms of the narrative length, structural organization and coherence. In particular, both groups show equivalent ability to relate narrative components to form a hierarchical coherent structure that allows them to communicate their unique perspectives on the recounted events as a means of expressing individual and/or cultural identities. Clearly, analyzing children's narratives through the lenses of a culturally sensitive framework enhances and/or broadens the portrayal of African-American narrators, and should become a part of educators' culturally sensitive pedagogy. As educators embrace a more diverse view of narrative, they acquire more effective means to illuminate diverse learners' expressions of personal and cultural meanings and more fully engage them in narrative-based classroom learning.

In contrast, the results of narrative analysis using Episodic Analysis that focuses on episodic organization promoted within the conventional school narrative expectations indicate several differences across the groups. When compared in terms of the overall narrative length and the length of episodes, personal narratives of African-American students are shorter. Furthermore, African-American students include more episodes (per narrative) in both fictional and personal narratives. Taken together, this pattern of performance resembles topic-associating, a well-documented narrative style in some African-American communities (e.g., Champion, 2003). Characterized by recurring themes related to time, place, and characters, this style allows the narrator to simultaneously inform and persuade their audience in order to communicate personal and social identity (Bidell, et al., 1997; Champion, 2003; Hicks, 1993; Michaels, 1991). In the classroom, this style may be of particular value for increasing participation in activities that foster inferential thinking, understanding interpersonal relationships and multiple perspective taking.

Further, while recounting personal experiences, African-American students include more information about their internal responses to the initiating narrative event (s) while they incorporate all other structural components with comparable frequency. This emphasis on the relationship among their goals, thoughts, feelings, and actions that implicitly guide the audience in understanding of the narrator's motivational behavior may be indicative of the narrator's preference to engage in narrating as an interactional social event (i.e., produce performative narratives), a narrative style common in some African-American children. Consequently, the narrator may interpret the narrative task as a means of not only recounting events but also expressing own identity and establishing specific social relationships with the audience (Bidell, et al., 1997; Cazden, 1999; Champion, 2003). In the classroom, this approach to narrative-based activities may offer unique opportunities to enhance social networking (e.g., cooperative learning, peer tutoring) and to build a sense of inclusive learning community.

In addition, African-American students less frequently organized their fictional (but not personal) narratives in the form of complete episodes that include an obstacle and an ending, along with a goal, attempt, and outcome. This tendency may be accounted for by well-documented cultural differences related to children's familiarity with fictional narratives (e.g., make-believe stories) (Bidell et al., 1997). Typically, middle-class Caucasian children are extensively exposed to literate-like, topic-centered stories that explicitly relate goals, obstacles, attempts, and outcomes (Hicks, 1993). In contrast, African-American children are often socialized into narrative styles that de-emphasize linear problem-solving sequencing in favor of thematic organization (Bidell et al., 1997; Hicks, 1993; Schick \& Melzi, 2010). However, teachers who value episodically structured narratives may perceive other narrative patterns as less suitable for organizing fictional narratives and, consequently diminish student opportunities to demonstrate their linguistic and intellectual abilities and engage in narrative-based learning (Currenton, 2011; Gay, 2000; Wiley, 2005). Culturally competent educators should develop a repertoire of strategies to assist students in mastering episodically organized fictional narratives while encouraging diversity in narrative coherence patterns. As this study evidences, narrative abilities may not generalize across narrative genres, resulting in a variation in student narrative performance depending on the content (personal versus fictional) and/or specific features of narrative tasks. Thus, instructional strategies aiming at enhancing narrative skills should facilitate a generalization of narrative competencies across narrative genres. 
The study results should be interpreted with caution given several of its limitations. Importantly, African-American and Caucasian students differ with respect to the background characteristics that have been associated with narrative competencies and preferences (Cazden, 1999; Champion, 2003; Michaels, 1991; Reese et al., 2010a). First, most of the participants eligible for free/reduced lunch were African-Americans. Similarly, the majority of African-American participants attended urban schools whereas all Caucasian peers were enrolled in suburban schools. Another factor that may have influenced the current results pertains to the differences in the characteristics of students with learning disabilities in each group. Compared to Caucasian participants with learning disabilities, African-American counterparts more often were identified as having difficulties in reading, writing, and mathematic, and were receiving less instruction in general education settings. These differences need to be considered in the light of the existing research-based evidence of the relationship between the level of narrative abilities and academic achievement (Hicks, 1996; McCabe, 1997; Roth et al, 1996; Schachter \& Craig, 2013), as well as the linguistic, academic and intellectual characteristics of students with learning disabilities (Celinska, 2004).

\section{References}

Artiles, A. J. (2002). Culture in learning: The next frontier in reading difficulties research. In R. Bradley, L. Danielson, \& D. P. Hallahan (Eds.), Identification of learning disabilities: Research to policy (pp. 693-701). Hillsdale, NJ: Lawrence Erlbaum.

Bidell, T. R., Hubbard, L. J., \& Weaver, M. (1997). Story structure in a sample of African American children: Evidence for a cyclical story schema. Paper presented at the Biennial Meeting of the Society for Research in Child Development. Washington, DC: ERIC Document ED 410578.

Blanchett, W. J. (2006). Disproportionate representation of African American students in special education: Acknowledging the role of white privilege and racism. Educational Researcher, 35(6), 24-28. http://dx.doi.org/10.3102/0013189X035006024

Blank, M. (2002). Classroom discourse: A key to literacy. In K. G. Butler \& E. R. Silliman (Eds.), Speaking, reading, and writing in children with language learning disabilities: New paradigms in research and practice (pp. 151-173). Mahwah, NJ: Lawrence Erlbaum Associates.

Bloome, D., Katz, L., \& Champion, T. (2003). Young children's narratives and ideologies of language in classrooms. Reading and Writing Quarterly, 19(2), 205-223. http://dx.doi.org/10.1080/10573560390196807

Bruner, J. (1991). The narrative construction of reality. Critical Inquiry, 18(1), 1-21.

Cazden, C. B. (1988). Classroom discourse. Portsmouth, NH: Heinemann.

Cazden, C. B. (1999). The language of African American students in classroom discourse. In C. T. Adger, D. Christian, \& O. Taylor (Eds.), Making the connection: Language and academic achievement among African American students: Proceedings of a Conference of the Coalition on Language Diversity in Education (pp. 31-52). ERIC Document ED 430402.

Celinska, D. (2009). Narrative voices of early adolescents: Influences of learning disability and cultural background. International Journal of Special Education, 24(3), 150-172.

Celinska, D. K. (2004). Personal narratives of students with and without learning disabilities. Learning Disabilities Research and Practice, 19(2), 83-98. http://dx.doi.org/10.1111/j.1540-5826.2004.00092.x

Champion, T. B. (2003). Understanding storytelling among African American children: A journey from Africa to America. Mahwah, NJ: Lawrence Erlbaum Associates.

Currenton, S. M. (2006). Oral storytelling: A cultural art that promotes school readiness. Young Children, 61, 78-89. http://dx.doi.org /10.1080/10409281003680578

Currenton, S. M. (2011). Understanding the landscapes of stories: The association between preschoolers' narrative comprehension and production skills and cognitive abilities. Early Child Development and Care, 181(6), 791-808. http://dx.doi.org /10.1080/03004430.2010.490946

Dickinson, D. K., Golinkoff, R. M., \& Hirsh-Pasek, K. (2010). Speaking out for language: Why language is central to reading development. Educational Researcher, 39(4), 305-310. http://dx.doi.org/10.3102/0013189X10370204

Donovan, S., \& Cross, C. (2002). Minority students in special and gifted education. Washington, DC: National Academy Press. 
Dyson, A. H. (1994). "I’m gonna express myself”: The politics of story in the children's worlds. In A. H. Dyson, \& C. Genishi (Eds.), The need for story: Cultural diversity in classroom and community (pp. 155-171). Urbana, IL: National Council of Teachers of English. ERIC Document ED 365991.

Fillmore, C. (1968). The case for case. In F. Bach, \& R. Harms (Eds.), Universals in linguistic theory (pp. 1-90). New York: Holt, Rinehart, \& Winston.

Friend, J. A. (1976). Traditional grammar: A short summary. Carbondale: Southern Illinois University Press.

Gardner-Neblett, N., Pungello, E. P., \& Iruka, I. U. (2012). Oral narrative skills: Implications for the reading development of African American children. Child Development Perspectives, 6(3), 218-224. http://dx.doi.org/10.1111/j.1750-8606.2011.00225.x

Gay, G. (2000). Culturally responsive teaching. New York, NY: Teachers College Press.

Gee, J. P., \& Green, J. L. (1998). Discourse analysis, learning, and social practice: A methodological study. Review of Research in Education, 23, 119-169. http://dx.doi.org/10.3102/0091732X023001119

Godley, A. J., Sweetland, J., Wheeler, R. S., Minnici, A., \& Carpenter, B. D. (2006). Preparing teachers for dialectically diverse classrooms. Educational Researcher, 35(8), 37. http://dx.doi.org/10.3102/0013189X035008030

Gutierrez, K. D., \& Rogoff, B. (2003). Cultural ways of learning: Individual traits or repertoires of practice. Educational Researcher, 32(5), 19-25. http://dx.doi.org/10.3102/0013189X032005019

Hester, E. J. (1996). Narratives of young African American children. In A. G. Kamhi, K. E. Pollock, \& J. L. Harris (Eds.), Communication development and disorders in African American children: Research, assessment, and intervention (pp. 227-246). Baltimore, MD: Paul H. Brookes Publishing, Inc.

Hester, E.J. (2010). Narrative correlates of reading comprehension in African American children. Contemporary Issues in Communication Science and Disorders, 37, 73-85. http://dx.doi.org/1092-5171/10/3701-0073

Hicks, D. (1993). Narrative discourse and classroom learning: An essay response to Egan's "Narrative and learning: A voyage of implications." Linguistics and Education, 5, 127-148.

Hicks, D. (1996). Discourse, learning, and teaching. In M. W. Apple (Ed.), Review of research in education, Vol. 23 (pp. 119-169). Washington, DC: AERA.

Hosp, J. L., \& Reschly, D. J. (2004). Disproportionate representation of minority students in special education: Academic, demographic, and economic predictors. Exceptional Children, 70(2), 185-199.

Kea, C. D., \& Utley, C. A. (1998). To teach me is to know me. The Journal of Special Education, 32(1), 44-47. http://dx.doi.org/10.1177/001440290407000204

Klingner, J. K., Artiles, A. J., Kozleski, E., Harry, B., Zion, S., Tate, W., Duran, G. Z. \& Riley, D. (2005). Addressing the disproportionate representation of culturally and linguistically diverse students in special education through culturally responsive educational systems. Education Policy Analysis Archives, 13(38). Retrieved on June 30, 2013 from http://epaa.asu.edu/epaa/v13n38/

Labov, W. (1972). Language in the inner city. Philadelphia: University of Pennsylvania Press.

Lue, M. S., Green, C. E, \& Smalley, S. Y. (2002). Communication skills of African American learners with disabilities. In: F. E. Obiakor, \& B. A. Ford (Eds.), Creating successful learning environments for African American learners with exceptionalities (pp. 107-117). Thousand Oaks: Corwin Press.

Mainess, K. J., Champion, T. B., \& McCabe, A. (2002). Telling the unknown story: Complex and explicit narration by African American preadolescents - preliminary examination of gender and socioeconomic issues. Linguistics and Education, 13(2), 151-173.

McCabe, A. (1997). Developmental and cross-cultural aspects of children's narration. In M. Bamberg (Ed.), Narrative development: Six approaches (pp. 137-174). Mahwah, NJ: Lawrence Erlbaum Associates.

Michaels, S. (1991). The dismantling of narrative. In A. McCabe, \& C. Peterson (Eds.), Developing narrative structure (pp. 303-351). Hillsdale, NJ: Lawrence Erlbaum Associates.

Moore, P. S. (2004). The use of social stories in a psychology service for children with learning disabilities: A case study of a sleep problem. British Journal of Learning Disabilities, 32(2), 133-138. http://dx.doi.org/10.1111/j.1468-3156.2004.00278.x 
Nelson, N., \& Van Meter, A. M. (2007). Measuring written language ability in narrative samples. Reading and Writing Quarterly, 23(3), 287-309. http://dx.doi.org/10.1080/10573560701277807

Petersen, D. B., \& Spencer, T. D. (2013). Test of Personal Generation: School Age. Language Dynamics Group. Retrieved June 5, 2013 from http://www.LanguageDynamicsGroup.com

Peterson, C., \& McCabe, A. (1983). Developmental psycholinguistics: Three ways of looking at a child's narrative. New York: Plenum Press.

Price, J. R., Roberts, J. E., \& Jackson, S. C. (2006). Structural development of the fictional narratives of African American preschoolers. Language, Speech, and Hearing Services in Schools, 37, 178-190. http://dx.doi.org/10.1044/0161-1461(2006/020)

Quall, C. D., O’Brien, R. M, Blood, G. W., \& Hammer, C. S. (2003). Contextual variation, familiarity, academic literacy, and rural adolescents' idiom knowledge. Journal of Speech, Language, and Hearing Services in Schools, 34, 69-79. http://dx.doi.org/10.1044/0161-1461(2003/007)

Reese, E., Leyva, D., Sparks, A., \& Grolnick, W. (2010). Maternal elaborative reminiscing increases low-income children's narrative skills relative to dialogic reading. Early Education and Development, 21, 318-342. http://dx.doi.org/10.1080/10409289.2010.481552

Reese, E., Suggate, S., Long, J., \& Schaughency, E. (2010). Children's oral narrative and reading skills in the first three years of reading instruction. Reading and Writing, 23, 627-644. http://dx.doi.org/10.1007/s11145-009-9175-9

Roth, F. P., Speece, D. L., Cooper, D. H., \& De La Paz, S. (1996). Unresolved mysteries: How do metalinguistic and narrative skills connect with early reading? The Journal of Special Education, 30(3), 257-277.

Schachter, R. E., \& Craig, H. K. (2013). Students' production of narrative and AAE features during an emergent literacy task. Language, Speech, and Hearing Services in Schools, 44, 227-238. http://dx.doi.org/10.1044/0161-1461(2013/12-0034)

Schick, A., \& Melzi, G. (2010). The development of children's oral narratives across contexts. Early Childhood and Development, 21, 293-317. http://dx.doi.org/10.1080/10409281003680578

Silliman, E. R., Wilkinson, L. C., \& Turner, C. R. (2002). Language variation and struggling readers: Finding patterns in diversity. In K. G. Butler, \& E. R. Silliman (Eds.), Speaking, reading, and writing in children with language learning disabilities: New paradigms in research and practice (pp. 109-148). Mahwah, NJ: Lawrence Erlbaum Associates.

Skiba, R. J., Poloni-Staudinger, L., Gallini, S, Simmons, A. B., \& Feggins-Azziz, R. (2006). Disparate access: The disproportionality of African American students with disabilities across educational environments. Exceptional Children, 72(4), 411-424. http://dx.doi.org/10.1177/001440290607200402

Snow, C. E., Burns, M. S., \& Griffin, P. (1998). Preventing reading failure in young children. Washington, DC: National Academy Press.

Stein N. L. (1988). The development of children's storytelling skills. In M. B. Franklin, \& S. Barten (Eds.), Child language: A reader (pp. 282-279). New York: Oxford University Press.

Stein, N. L., \& Albro, E. R. (1997). Building complexity and coherence: Children's use of goal-structured knowledge in telling stories. In M. Bamberg (Ed.), Narrative development: Six approaches (pp. 5-44). Mahwah, NJ: Lawrence Erlbaum Associates.

Tabors, P. O., Snow, C. E., \& Dickinson, D. K. (2001). Homes and schools together: Supporting language and early literacy development. In D. K. Dickinson, \& P. O. Tabors (Eds.), Beginning literacy with language. Baltimore, MD: Brookes.

Wiley, T. G. (2005). Literacy and language diversity in the United States (2nd ed.). Washington, DC: Center for Applied Linguistics.

Zigo, D. (2001). From familiar worlds to possible worlds: Using narrative theory to support struggling readers' engagement with texts. Journal of Adolescent and Adult Literacy, 45(1), 62-71. 